\title{
Angiographic study of the middle cerebral artery in chronic infantile hemiplegia ${ }^{1}$
}

\author{
MARK DYKEN ${ }^{2}$ \\ From the Research Unit, New Castle State Hospital, New Castle, Indiana (formerly New Castle State Village \\ for Epileptics), and the Department of Neurology, Indiana University Medical Center, Indianapolis, Indiana \\ U.S.A.
}

The clinical syndrome of unilateral weakness, spasticity, and hypoplasia of the extremities secondary to contralateral brain damage occurring prenatally or during infancy was present in $\mathbf{4 0}$ patients who were studied by carotid angiography. Changes in the middle cerebral artery in children with this condition have been described by Lefebvre, Lepintre, Fauré, and Perez (1956) and by Taveras and Poser (1959). This investigation pertains to alterations in calibre, structure, and distribution of this vessel. Our primarily adult population demonstrated variations from the usual descriptions of children's vasculature.

\section{MATERIAL}

Carotid angiography was performed on $\mathbf{4 0}$ patients with chronic infantile hemiplegia from an institution for chronic neurological diseases. In all but one, both middle cerebral arteries were visualized. In the exception, the middle cerebral artery supplying the hemisphere of maximal dysfunction was visualized. The ages ranged from 7 to 55 years with a median of 26 . All but one had epilepsy. Eighteen were female and 22 were male. Twenty of the patients had right hemiplegia and 20 had left hemiplegia. The history of onset was unreliable but was said to have occurred before 2 years of age in 27 of the 31 cases where a history could be obtained.

All patients had skull radiographs and multiple E.E.G.s. Thirty-six had pneumoencephalograms. Cerebral blood flow and cerebral vascular resistance were studied in 31 and cerebral oxygen consumption in 27 , by the nitrous oxide method using the Fick principle as described by Kety and Schmidt (1945).

\section{METHOD}

At the time of angiography a lumbar puncture was performed with a special thin-walled, no. 17 gauge, spinal needle through which Teflon tubing was inserted into the subarachnoid space. The needle was then withdrawn and

${ }^{1}$ Study supported in part by a grant from the Indiana Heart Association.

${ }^{2}$ Present address: Department of Neurology, Indiana University Medical Center, 1100 W. Michigan Street, Indianapolis, Indiana, U.S.A. the Teflon tubing left in place for continuous pressure recordings. Both common carotid arteries and botio jugular bulbs were cannulated with no. 18 gauge spinaf needles. The artery was cannulated as low in the neck as. possible to avoid changes secondary to carotid sinus stimulation. Venous and arterial pressures were contin $=$ uously recorded from these sites. The E.E.G. and E.K.G.W were also recorded continuously. Cerebral blood flow measurements were obtained before and after angio graphy. Bilateral carotid angiograms were performe o using $5 \mathrm{ml}$. quantities of sodium diatrizoate, $50 \%$ (Hypaque), as the contrast medium. Radiographs were taken at least every second after injection, using Sanchez-Perez seriographic automatic cassette changege

\section{RESULTS}

Changes in the middle cerebral artery and in its afeete of distribution on the side of maximal brain damage? were striking in 18 cases. Fifteen of these dem $\overrightarrow{\text { ine }}$ strated a small calibre, middle cerebral artery (less than two-thirds the size of a comparable vessel) on the side of the damaged hemisphere (Fig. 1a-g) Three showed other abnormalities. In one, the middle cerebral artery trunk was replaced by a collection of vessels in the Sylvian fissure (Fig. 2). In another, the internal carotid trunk seemed to be partially occluded distal to the posterior communicating artery. In this instance, during the early arterial phase, the ascend ing frontal branches of the middle cerebral artery, an abnormal cluster of vessels in its distribution, and. the entire posterior cerebral artery were visualized As the arterial phase of the posterior cerebral arteryo faded, reflux filling of vessels in the irrigation areas? of the middle and anterior cerebral arteries was observed (Fig. 3a, b). The third patient had abnor 0 mal clumps of vessels completely replacing all nor mal arteries above the tentorium (Fig. 4a, b).

Measurements described by Taveras and Poser (1959) were made. They noted that in cerebra? hemiatrophy the cortical vessels were separated from the inner table of the skull by a distance of 4 or $5 \mathrm{~mm}$. or more. In 36 of the 40 predominantly adult 


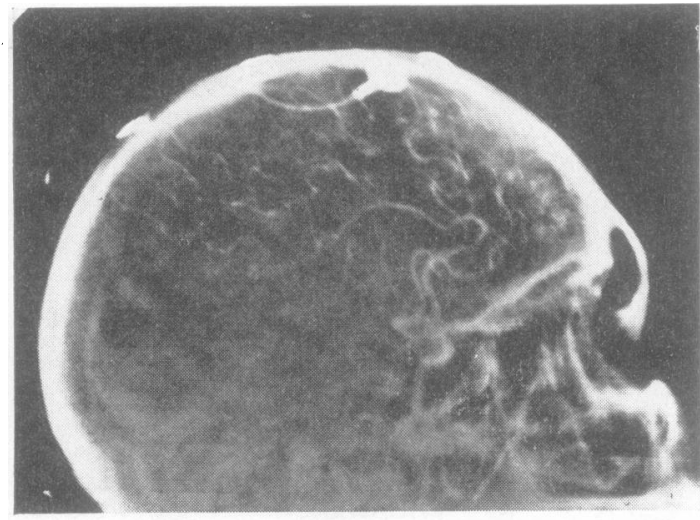

FIG. 2

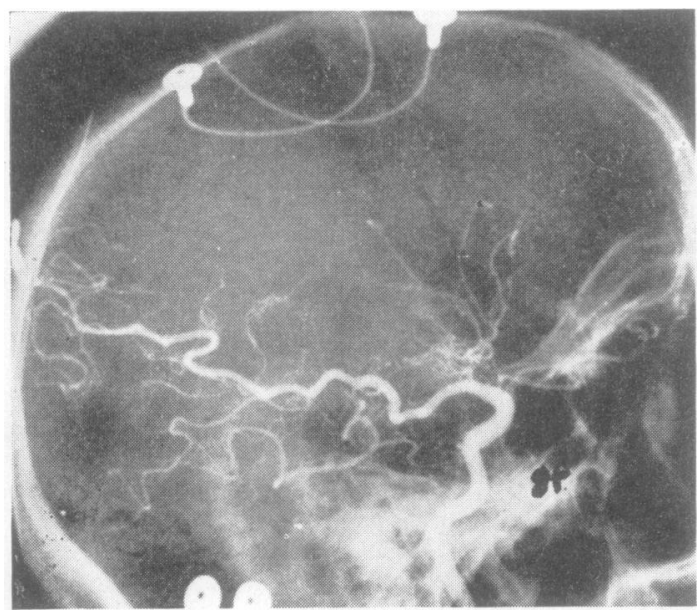

FIG. $3 a$

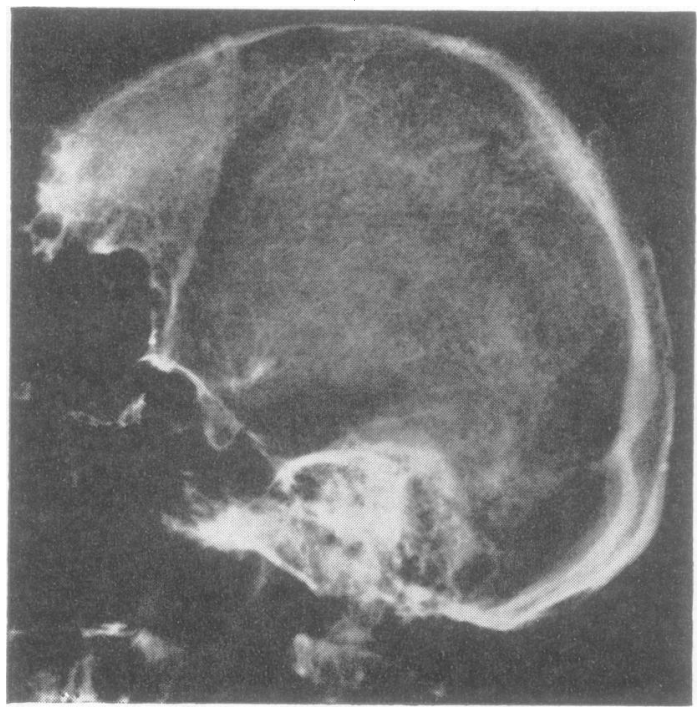

FIG. $4 \mathrm{a}$
FIG. 2. Carotid arteriogram demonstrating an abnorma collection of vessels and clumps of dye in the distribution of the left middle cerebral artery.

FIG. 3a. At 0 seconds the right lateral carotid arteriogrant demonstrates filling of the posterior cerebral artery and the ascending frontal branches of the middle cerebral arteryo and an abnormal cluster of vessels.

3b At one second, vessels in the distribution of the middle and anterior cerebral artery are filling from the posteriof cerebral artery.

FIG. 4a. Right lateral carotid angiogram demonstrating clumps of vessels above the tentorium with no normap vasculature. 4b. Left lateral carotid angiogram demonstrating same $\frac{\bar{\Phi}}{\overline{\frac{D}{D}}}$
findings as Figure $4 \mathrm{a}$.

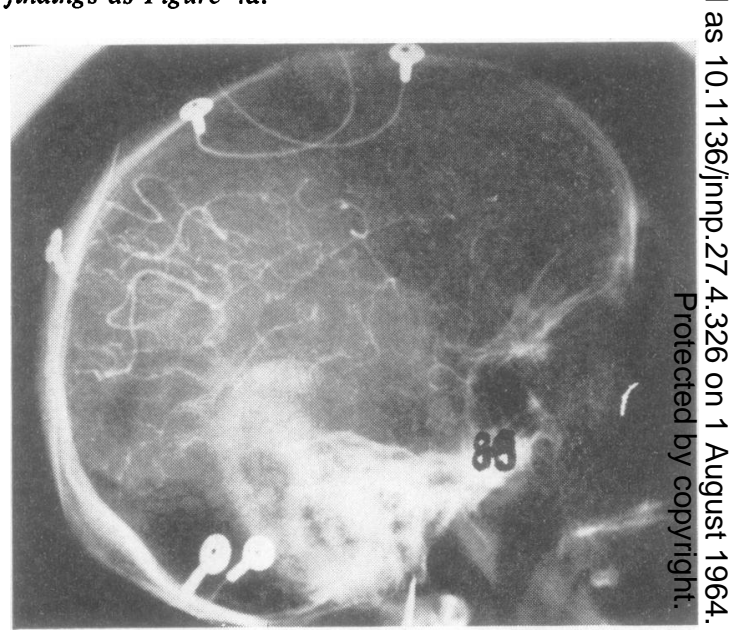

FIG. $3 b$

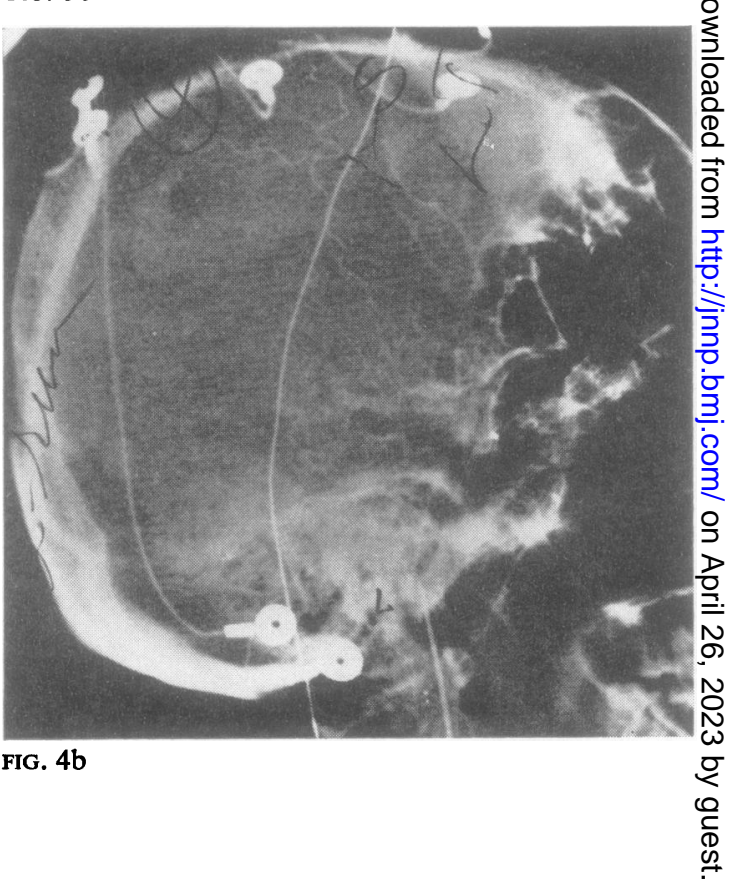




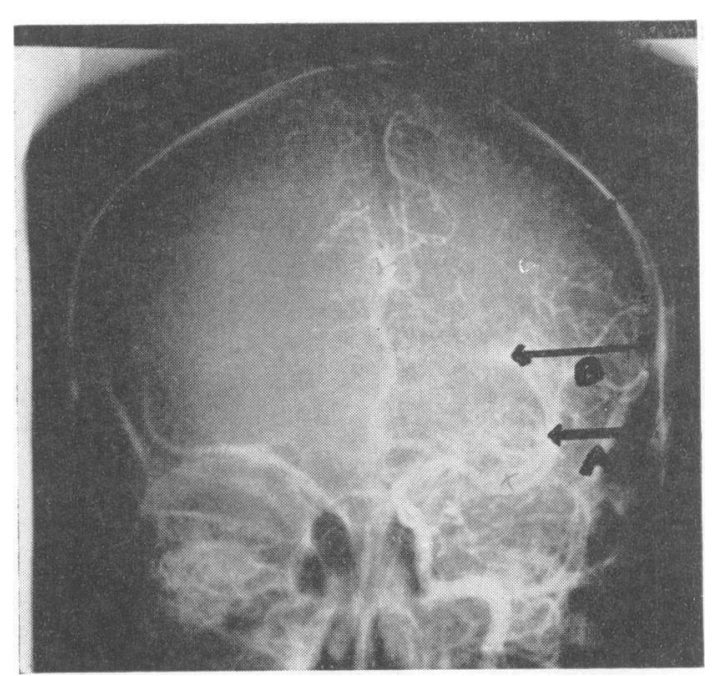

FIG. 5. Anterior posterior film of a left carotid arteriogram demonstrating separation of the cortical branches of the middle cerebral artery from the internal table and the $A$ and $B$ measurements of Taveras and Poser.

patients an adequate late arterial phase with filling of the surface vessels permitted reliable measurement (Fig. 5). Only eight displayed a separation of more than $3 \mathrm{~mm}$. In one, the distance was $6 \mathrm{~mm}$.; in seven it was 4 or $5 \mathrm{~mm}$.

Taveras and Poser (1959) made two other measurements: A, the distance between the inner table of the skull and the innermost limit of the middle cerebral vessels over the insula, and $B$, the distance between the inner table of the skull and the innermost limit of the middle cerebral vessels just before they leave the insula to emerge through the Sylvian fissure and over the surface of the hemisphere (Fig. 5). They reported that in 30 normal angiograms A ranged from 21 to $30 \mathrm{~mm}$. and B from 28 to $40 \mathrm{~mm}$., and that in children with hemiatrophy the distance for A was always less than the minimal normal and ranged between 14 and $19 \mathrm{~mm}$. A was measured in 35 and B in 36 of our cases bilaterally. The same measurements were made in a group of 32 controls. The controls were selected by studying 51 consecutive carotid angiograms performed in the fall of 1961 and spring of 1962 at the Indiana University Medical Centre. Cases that were not injected bilaterally showed a shift of the anterior cerebral artery, had a proven supratentorial tumour, or disclosed insufficient filling for measurement were discarded. Nineteen cases were thus eliminated. Nineteen of the $\mathbf{3 2}$ controls were normal, five demonstrated aneurysms, one had internal hydrocephalus, six demonstrated carotid artery occlusive disease, and one had a chromophobe adenoma of the pituitary. The arithmetical mean age of this group was $46.96 \pm 16^{1} 6^{1}$ years. Ten were female and 21 were male. In the hemiplegic group the mean measurement for $\mathrm{A}$ on the damaged side was $21.4 \pm 3.7 \mathrm{~mm}$. and on the unaffected side $26.6 \pm 2.92 \mathrm{~mm}$. In the controls it was $27.31 \pm 3.36 \mathrm{~mm}$. on the right and $27.34 \pm 3.4$ $\mathrm{mm}$. on the left. The mean measurement for B in the hemiplegic group was $27.61 \pm 5.18 \mathrm{~mm}$. on the damaged side and $34.47 \pm 3.78 \mathrm{~mm}$. on the opposite side. In the control group the $B$ measurement was $36.46 \pm 3.05 \mathrm{~mm}$. on the right and $36.84 \pm 3.18$ $\mathrm{mm}$. on the left. Although in the hemiplegic group the differences between the measurements on the damaged side and the undamaged side would occur by chance in less than one in a thousand times, the measurement by itself is of little value because of the considerable overlap with a non-infantile hemiplegic population. Therefore, in each patient in the study group, the measurement on the affected side was subtracted from that on the unaffected side, and in each case in the control group the larger measurement was subtracted from the smaller. The mean of the larger minus the small A measurements in the control group was $0.03 \pm 1.22 \mathrm{~mm}$., and in the hemiplegic group the mean of the damaged subtracted from the unaffected was $5 \cdot 20 \pm 4.5 \mathrm{~mm}$. In the control group the right minus the left $B$ measurements gave a mean of $0.344 \pm 1.20 \mathrm{~mm}$. In the hemiplegic group the mean difference between affected and unaffected sides was $6.86 \pm 4.9 \mathrm{~mm}$. The differences in A and B measurements between the control and the hemiplegic group were analysed and were significant. $P$ was less than 0.001 (Table I).

\section{DISCUSSION}

An unusually high incidence of gross abnormalities in the region of the middle cerebral artery $(45 \%)$ was noted in the cerebral hemisphere opposite the hemiplegia. Lefèbvre et al. (1956) found abnormalities of calibre and number of vessels in the region of the middle cerebral artery in 11 of $30(37 \%)$ children with infantile hemiplegia studied by angiography. Ford and Schaffer (1927) and Taveras and Poser (1959) suggested that such changes were secondary to vascular injury or thrombosis which took place at an earlier age and was followed by recanalization. Our case illustrated in Fig. $3 \mathrm{a}$ and $3 \mathrm{~b}$ demonstrated occlusion with the area of circulation of the middle and anterior cerebral arteries filling by reflux from anastomosis with the posterior cerebral artery. Duffy, Portnoy, Mauro, and Wehrle (1957), Teng and Goldenberg (1960), Goldstein and Burgess

${ }^{1}$ All standard deviations reported in this article and in the tables are the estimated standard deviation of the population (Croxton, 1959). 
TABLE I

ANALYSIS OF A AND B MEASUREMENTS OF TAVERAS AND POSER IN HEMIPLEGICS COMPARED WITH CONTROLS

\begin{tabular}{|c|c|c|c|c|}
\hline & $\begin{array}{l}\text { Study } \\
(\text { A-n-35 B-n-36 } \\
\text { Bad Side }(\mathrm{mm} .)\end{array}$ & Good Side (mm.) & $\begin{array}{l}\text { Control } \\
(n-32) \\
\text { Right }(\mathrm{mm} .)\end{array}$ & Left \\
\hline $\begin{array}{l}\text { Minimum A } \\
\text { Maximum A } \\
\text { Mean A } \\
\text { Standard deviation A } \\
\text { Probability of difference of A good minus A bad or A left minus A right } \\
\text { occurring by chance } \\
\text { Minimum B } \\
\text { Maximum B } \\
\text { Mean B } \\
\text { Standard deviation B } \\
\text { Probability of difference of B good minus B bad or B left minus B right } \\
\text { occurring by chance } \\
\text { Mean of A good minus A bad or A left minus A right } \\
\text { Standard deviation of differences A good minus bad and A left minus right } \\
\text { Mean of B good minus B bad or B left minus B right } \\
\text { Standard deviation of differences B good minus bad and B left minus right } \\
\text { Probability of difference of differences between A control and study being } \\
\text { due to chance } \\
\text { Probability of difference of differences between B control and study being } \\
\text { due to chance } \\
\text { Percentage of population that A differences will be } 3 \text { mm. or above } \\
\text { Percentage of population that B differences will be } 3 \text { mm. or above } \\
\\
\text { 1t test for non-independent samples (Croxton, 1959) } \\
{ }^{3} t \text { test for independent samples assuming unequal variances (Croxton, 1959) }\end{array}$ & $\begin{array}{ll}17 & \\
30 & \\
21 \cdot 4 & \\
3 \cdot 7 & \\
& \\
17 & \\
38 & \\
27 \cdot 61 & \\
5 \cdot 18 & \end{array}$ & $\begin{array}{ll} & 19 \\
& 32 \\
& 26 \cdot 6 \\
& 2 \cdot 92 \\
& \\
& \\
<0.001 & \\
& 24 \\
& 41 \\
& 34 \cdot 47 \\
& 3 \cdot 78 \\
& \\
0.001 & \\
2 & \\
5 & \\
36 & \\
9 & \end{array}$ & $\begin{array}{rr} & 0.9> \\
27 & \\
41 & \\
36.46 & \\
& 3.05 \\
& \\
& 0.2> \\
& \\
& \\
& 1 \\
& 0 \\
& 1\end{array}$ & 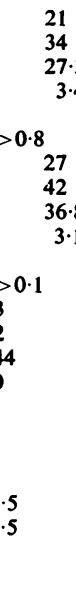 \\
\hline
\end{tabular}

(1958), Mymin (1960), and others have demonstrated that thrombosis can occur in the arteries supplying the brain in childhood. Why thrombosis occurs is not established. Duffy et al. (1957) found congenital abnormalities in the vessel at the site of the thrombosis. Mymin's case was associated with a congenital heart disease. Norman and Urich (1957) described the brain of a 15-year-old male who developed a left hemiplegia at the age of 6 months and who had a dissecting aneurysm of the right middle cerebral artery which was probably followed by occlusion, thrombosis, and subsequent recanalization. Detailed examination of the artery gave no clue to the aetiology of the dissection. Wolman (1959) reported a 19-year-old girl who had a right hemiplegia, probably dating from birth, whose brain demonstrated a dissecting aneurysm of the left middle cerebral artery in which there was a gross congenital defect of the media and internal elastic lamina. Bailey (1960) presented a case of infantile hemiplegia whose carotid angiogram demonstrated a smallsized middle cerebral artery which was identical to those reported in this paper. The pathological study demonstrated disseminated areas of tissue dysgenesis in both hemispheres but most severe on the left. These were foci of vascular disturbances of growth combined with disorganized brain tissue and areas of arteriovenous malformation. Although the weight of evidence suggests that the described abnormalities of the middle cerebral arteries are secondary arterial occlusion with recanalization and revasculä ization, it is suggested that, in addition to possible arteritis and embolization, congenital defects in theo vasculature must be considered.

Only eight of the adequately studied 36 cases of this series demonstrated significant separation of theo cortical vessels from the inner table of the skull. This suggests that the probability of this finding decreases $\overrightarrow{\vec{B}}$ as patients grow older. Such a separation would be 3 more likely in young children before the skull has a? chance to thicken and form sinuses to fill the space evacuated by the damaged brain.

The results of the measurements by Taveras and Poser of A1-A2 and B1-B2 are described in the texto and Table I. My observations indicate that the 3 differences of one or two millimetres can result from subjective errors in measurement and can be altered 3 by bias if one knew the side of suspected abnormalityo and did not measure each side without knowledge of the other. For this reason, an arbitrary difference ofo $3.00 \mathrm{~mm}$. was selected above which angiographic findings were classed as abnormal and below whicho they were classed as normal. Prediction of the pro- N portion of future hemiplegics who would fall aboven this $3.00 \mathrm{~mm}$. difference and the proportion of $\sigma$ normals who would fall below this $3.00 \mathrm{~mm}$. was required. Using A1-A2 equal to or greater than 3.00 응 $\mathrm{mm}$., the risk of misclassifying an infantile hemi- 
plegic's angiogram as normal is between 30 and $35 \%$, i.e., would correctly classify 65 to $70 \%$, and the risk of misclassifying a normal as hemiplegic is between $1 \%$ and $2.5 \%$ (Table I). Using B1-B2 equal to or greater than $3.00 \mathrm{~mm}$., the risk of misclassifying a hemiplegic as normal is between 20 and $25 \%$, i.e., between $75 \%$ and $80 \%$ correctly classified, and the risk of misclassifying a normal as hemiplegic is between $1 \%$ and $2.5 \%$ (Table I). Therefore, if a patient had a difference between the $\mathrm{A}$ or between the B measurements of $3.00 \mathrm{~mm}$. or greater, the probability would be high that his cerebral hemisphere was not normal; and, if a space-taking lesion were excluded, he had severe chronic structural damage of the hemisphere on the side of the lower measurement.

\section{SUMMARY}

Forty chronic infantile hemiplegic patients confined to a hospital for neurologically diseased patients were studied by carotid angiography. Abnormalities were visualized in the distribution of the middle cerebral artery on the side of the 'damaged' hemisphere in $18(46 \%)$. In 15 the artery was of small calibre (less than two-thirds the size of a comparable vessel). In one the artery was replaced by an abnormal collection of vessels in the Sylvian fissure. In another the internal carotid artery trunk was partially occluded distal to the posterior communicating artery. In still another all arteries above the tentorium were replaced by abnormal clusters of vessels. A review of the literature suggested that these abnormalities are secondary to arterial occlusion with recanalization or revascularization, but that the original thrombosis in many cases was secondary to congenital defects in the vasculature.

Measurements of the distance from a trunk of the middle cerebral artery to the inner table of the skull as reported by Taveras and Poser (1959) were compared with those made in this series. Their measurements differed from those of our population of older patients. Therefore, comparisons were made between the two sides of the hemiplegic population and 32 controls and the results were analysed statistically. By determining differences in these measurements, unilateral chronic brain damage could be determined at a high level of reliability.

My thanks go to Dr. James A. Norton, Jr., biostatistician, who served as statistical consultant, and to Dr. William E. Murray, Superintendent of New Castle State Hospital, New Castle, Indiana, and all his staff.

\section{REFERENCES}

Bailey, O. T. (1960). The pathology of juvenile hemiplegia. $G P$ (Kansas), 21, April, pp. 88-97.

Croxton, F. (1959). Elementary Statistics with Applications in Medicine and the Biological Sciences. Dover Publications, New York.

Duffy, P. E., Portnoy, B., Mauro, J., and Wehrle, P. F. (1957). Acute infantile hemiplegia secondary to spontaneous carotid thrombosis. Neurology (Minneap.), 7, 664-666.

Ford, F. R., and Schaffer, A. J. (1927). The etiology of infanti'e acquired hemiplegia. Arch. Neurol. Psychiat., 18, 323-347.

Fraser, D. A. S., and Guttman, I. (1956). Tolerance regions. Ann. Math. Stat., 27, 162-179.

Goldstein, S. L., and Burgess, J. P. (1958). Spontaneous thrombosis of the internal carotid artery in a 7-year-old child. A.M.A.J. Dis. Child., 95, 538-540.

Kety, S. S., and Schmidt, C. F. (1945). The determination of cerebral blood flow in man by the use of nitrous oxide in low concentions. Amer. J. Physiol., 143, 53-66.

Lefèbvre, J., Lepintre, J., Fauré, C., and Perez, J. (1956). Résultats de l'angiographie cérébrale au cours des hémiplégies cérébrales infantiles. Acta radiol. (Stockh.), 46, 456-465.

Mymin, D. (1960). Carotid thrombosis in childhood. Arch. Dis. Child., 35, $515-518$.

Norman, R. M., and Urich, H. (1957). Dissecting aneurysm of the middle cerebral artery as a cause of acute infantile hemiplegia. J. Path. Bact., 73, 580-582.

Taveras, J. M., and Poser, C. M. (1959). Roentgenologic aspects of cerebral angiography in children. Amer. J. Roentgenol., 82, 371-391.

Teng, P., and Goldenberg, E. D. (1960). Thrombosis of internal carotid artery in a 5-year-old child. A.M.A. J. Dis. Child., 99, 228-230.

Wolman, L. (1959). Cerebral dissecting aneurysms. Brain, 82, 276-291. 